\title{
A systematic review and meta-analysis of the effect of preoperative exercise intervention on rehabilitation after total knee arthroplasty
}

\author{
Dun Wang ${ }^{1,2}$, Tao Wu ${ }^{1,2}$, Yi Li ${ }^{1,2}$, Ling $\mathrm{Jia}^{3}$, Jing $\operatorname{Ren}^{3}$, Lin Yang ${ }^{1,2}$ \\ ${ }^{1}$ Department of Rehabilitation Medicine, West China Hospital, Sichuan University, Chengdu, China; ${ }^{2}$ Key Laboratory of Rehabilitation Medicine, \\ West China Hospital, Sichuan University, Chengdu, China; ${ }^{3}$ International Medical Center, West China Hospital, Sichuan University, Chengdu, \\ China \\ Contributions: (I) Conception and design: D Wang; (II) Administrative support: L Yang; (III) Provision of study materials or patients: T Wu; (IV) \\ Collection and assembly of data: Y Li, L Jia, J Ren; (V) Data analysis and interpretation: D Wang; (VI) Manuscript writing: All authors; (VII) Final \\ approval of manuscript: All authors. \\ Correspondence to: Lin Yang. Department of Rehabilitation Medicine, West China Hospital, Sichuan University, Chengdu, China; Key Laboratory of \\ Rehabilitation Medicine, West China Hospital, Sichuan University, Chengdu, China. Email: ansonwest@163.com.
}

Background: A number of researches indicated preoperative functional exercise may improve the rehabilitation progress. This study aimed to investigate the effect of preoperative exercise intervention on rehabilitation before total knee arthroplasty (TKA) by literature retrieval and meta-analysis.

Methods: Embase, Cochrane library, PubMed, Ovid, and ClinicalTrials.gov were selected as the search database platforms. All published English articles related to preoperative exercise of TKA from January 2000 to January 2021 were searched with the following keyword strategy: ("preoperative functional exercise" or "prehabilitation exercise") AND ("TKA" or "total knee arthroplasty"). After literature screened according to the inclusion and exclusion criteria, the risk of bias and quality of the included articles were evaluated. RevMan 5.3.5 software was used for analysis to obtain the forest plot and funnel plot.

Results: A total of 911 articles were preliminarily searched in this study, and 12 were finally included for the quantitative analysis, comprising 889 patients; the result showed after intervention, the experimental group patients had wider ROM flexion than the control group patients [mean difference $(\mathrm{MD})=4.28 ; 95 \%$ CI: 2.28 to $6.28 ; \mathrm{Z}=4.19 ; \mathrm{P}<0.0001$ ]; the experimental group patients were with higher quadriceps strength value than the control group ( $\mathrm{MD}=1.86,95 \% \mathrm{CI}$ : $0.58-3.15 ; \mathrm{Z}=2.84, \mathrm{P}=0.005$ ); the WOMAC score (The Western Ontario and McMaster Universities Osteoarthritis Index), were higher for the experimental group patients ( $M D=-10.59 ; 95 \% \mathrm{CI}:-11.88$ to $-9.29 ; \mathrm{Z}=16.03 ; \mathrm{P}<0.00001)$; and the standing and walking test index are higher $(\mathrm{MD}=-1.29,95 \% \mathrm{CI}:-1.90$ to $-0.67 ; \mathrm{Z}=4.08 ; \mathrm{P}<0.001)$; the quality of life score were higher too for the experimental group patients ( $M D=1.66$; 95\% CI: $1.13-2.20 ; \mathrm{Z}=6.08 ; \mathrm{P}<0.00001$ ).

Discussion: Preoperative exercise intervention before TKA can improve knee flexion and flexibility, reduce inflammatory pain and stiffness, improve muscle strength, improve joint function, and thus improve the quality of life of patients.

Keywords: Preoperative exercise intervention; total knee arthroplasty (TKA); rehabilitation effect; meta-analysis

Submitted Aug 31, 2021. Accepted for publication Oct 20, 2021.

doi: 10.21037/apm-21-2670

View this article at: https://dx.doi.org/10.21037/apm-21-2670 


\section{Introduction}

Arthritis and rheumatoid arthritis are the most common diseases leading to knee joint disease, which can cause muscle and nerve pain and loss of mobility, prevent patients from daily life and work (1). Total knee arthroplasty (TKA) is an effective treatment for severe knee osteoarthropathy, which can effectively correct joint deformity, reduce pain, improve knee function, and improve the quality of life of patients (2). Perioperative exercise rehabilitation exercises can pull and stretch muscles, strengthen muscles, improve local blood circulation, prevent complications such as nerve root adhesion, knee stiffness, and thrombosis, and promote the rapid healing of the knee joint (3). However, most recent studies in this field were focusing on postoperative functional exercise, less attention had been paid to the preoperative exercise intervention. In fact, limb functional exercise before TKA (preoperative exercise) is as important as that after TKA. Preoperative functional exercise can not only increase the strength of the muscles around the diseased joints, but also enhance the patient's physique, make it easier for the patient to adapt to postoperative functional exercise, and promote the early recovery of walking function (4). From the $21^{\text {st }}$ century onward, the number of researches on preoperative functional exercise to improve postoperative rehabilitation progress has gradually increased, but the intervention methods are diverse, the data indicators are not uniform, and the quality of the literature varies. A study conducted by Chen et al. (5) found that prehabilitation exercise was effective but the quality of evidence was low. Therefore, in this study, we used meta-analysis to collect more randomized controlled trial (RCT) articles with higher quality published in mainstream databases and performed quantitative analysis to understand the effect of preoperative exercise intervention. We present the following article in accordance with the PRISMA reporting checklist (available at https://dx.doi.org/10.21037/ apm-21-2670).

\section{Methods}

\section{Database and search strategy}

Embase, Cochrane library, PubMed, Ovid, ClinicalTrials. gov were selected as the search database platforms. All the published English-language literature related to preoperative exercise of TKA from January 2000 to January 2021 were searched for with the following keyword strategy: ("preoperative functional exercise" or "prehabilitation exercise") AND ("TKA" or "total knee artbroplasty").

\section{Inclusion criteria}

The inclusion criteria for literature were the following: (I) the study involved patients diagnosed as osteoarthritis (OA) and who underwent TKA (unilateral or bilateral) by the same plastic surgeon; (II) the patients had undergone TKA surgery for the first time; (III) all patients could walk freely or with the help of walking aids; (IV) the intervention measures included an experimental group and control group, with the experimental group undergoing preoperative exercise intervention, and the control group undergoing routine care without preoperative exercise intervention. Besides that, both the two groups were treated with the same preoperative medication and health education; (V) the study included an observation period of at least 6 weeks; (VI) at least 1 rehabilitation indicator was included; and (VII) the complete data for meta-analysis were provided with the rehabilitation indicators being expressed in the form of mean \pm standard deviation.

\section{The exclusion criteria}

The exclusion criteria for literature were the following: (I) studies involved patients who do not have the surgery for the first time or patients who already have surgeries 3 months before, or patients who undergo other type of surgery (such as total hip surgery THA); (II) studies in which the intervention was postoperative exercise; (III) literature consisting of investigations, case analyses, reviews, guidelines, systematic reviews, or nonrandomized controlled studies; (IV) studies with mixed intervention methods, such as exercise combined with other physical treatment devices; (V) studies in which the intervention method was unclear, or without a stated intervention frequency or intervention time; (VI) studies in which the rehabilitation indicators were missing, or from which meaningful data could not be derived (e.g., the data contained the median but not the mean); and (VII) 
literature for which the full text could not be obtained.

\section{Literature screening}

Two researchers conducted the database search, read the titles and abstracts to exclude the repeated articles, performed the preliminary screening according to the inclusion and exclusion criteria, obtained the full text of the articles after preliminary screening, read the full-text, and after screening the literature, decided upon the literature to be included in the final quantitative analysis. If there was conflict in opinions during this process and discussion cannot reach a consensus, a third person was invited to arbitrate.

\section{Literature quality evaluation and bias analysis}

Cochrane Reviewer's Handbook (5) was used to evaluate the risk of bias in the articles included in the study. The following 6 aspects were evaluated: (I) randomization method; (II) blinding method; (III) implementation of allocation concealment; (IV) data integrity; (V) selective reporting bias; and (VI) other biases. Each was classified as "low risk," "unclear," or "high risk". If the article was evaluated as low risk in 6 aspects, it was considered to be a level A article; if there was 1 or more "unclear" aspect, it was level B; if there was 1 or more "high risk" aspect, it was level C.

\section{Outcome indicators}

Rehabilitation outcome indicators after TKA included (I) Range of Motion, ROM; (II) The Western Ontario and McMaster Universities Osteoarthritis Index (WOMAC) (6); (III) Visual Analogue Scale (VAS); (IV) Timed Up and Go (TUG) test; (V) 6-Minute Walk Test (6 MWT); (VI) Stair Climbing Test (SCT); (VII) quadriceps strength; (VIII) The Short Form of Health Survey Questionnaire (SF-36); (IX) the Knee Injury and Osteoarthritis Outcome Score (KOOS), and (X) the Berg Balance Scale (BBS).

\section{Data extraction}

Two reviewers extracted the following data after reading the full text: author, publication year and month, number of grouped cases, age, gender ratio, intervention measures, intervention frequency, observation time, and rehabilitation indicators. If the data were presented as percentages, they were converted into the actual number of cases; all the indicators expressed as median (range) were discarded, and only the indicators expressed as mean and standard deviation were included. The observation points of rehabilitation indicators are based on the data within $1.5-3$ months (6-12 weeks) of the operation.

\section{Statistical methods}

(I) The meta-analysis was conducted using RevMan 5.3.5 software (Cochrane Collaboration). (II) Inverse variance statistics were used for continuous variables, and mean difference (MD) and 95\% CI were used to report statistics. $\mathrm{P}<0.05$ indicated that the difference was significant statistically. (III) Forest plot descriptive statistics were used for comparison. (IV) $\mathrm{I}^{2}$ analysis and $\mathrm{Q}$ test were used to evaluate the literature heterogeneity, $\mathrm{I}^{2}>50 \%$ or $\mathrm{P}<0.1$ was used to indicate the heterogeneity of results, and a random effects model was used to obtain the odd ratio $(\mathrm{OR})$ value; otherwise, a fixed effects model was used to obtain the OR value. (V) If heterogeneity between the articles was suggested and when the source of heterogeneity could not be judged, a case-by-case exclusion method was used for sensitivity analysis. (VI) Funnel plot was used to indicate publication bias.

\section{Results}

\section{Literature screening results}

In this study, 911 articles were preliminarily searched, after deduplication, 284 duplicate articles were excluded, and the remaining 627 entered the next round of inspection. Finally 12 articles were included in the quantitative analysis, comprising 889 patients, as shown in Figure 1. List of basic characteristics, intervention measures, and rehabilitation indicators from all the studies are shown in Table 1.

\section{Literature quality and bias evaluation}

All studies included in the meta-analysis reported the postoperative observation time points at 3,6 , and 


\section{Identification of studies via databases and registers}
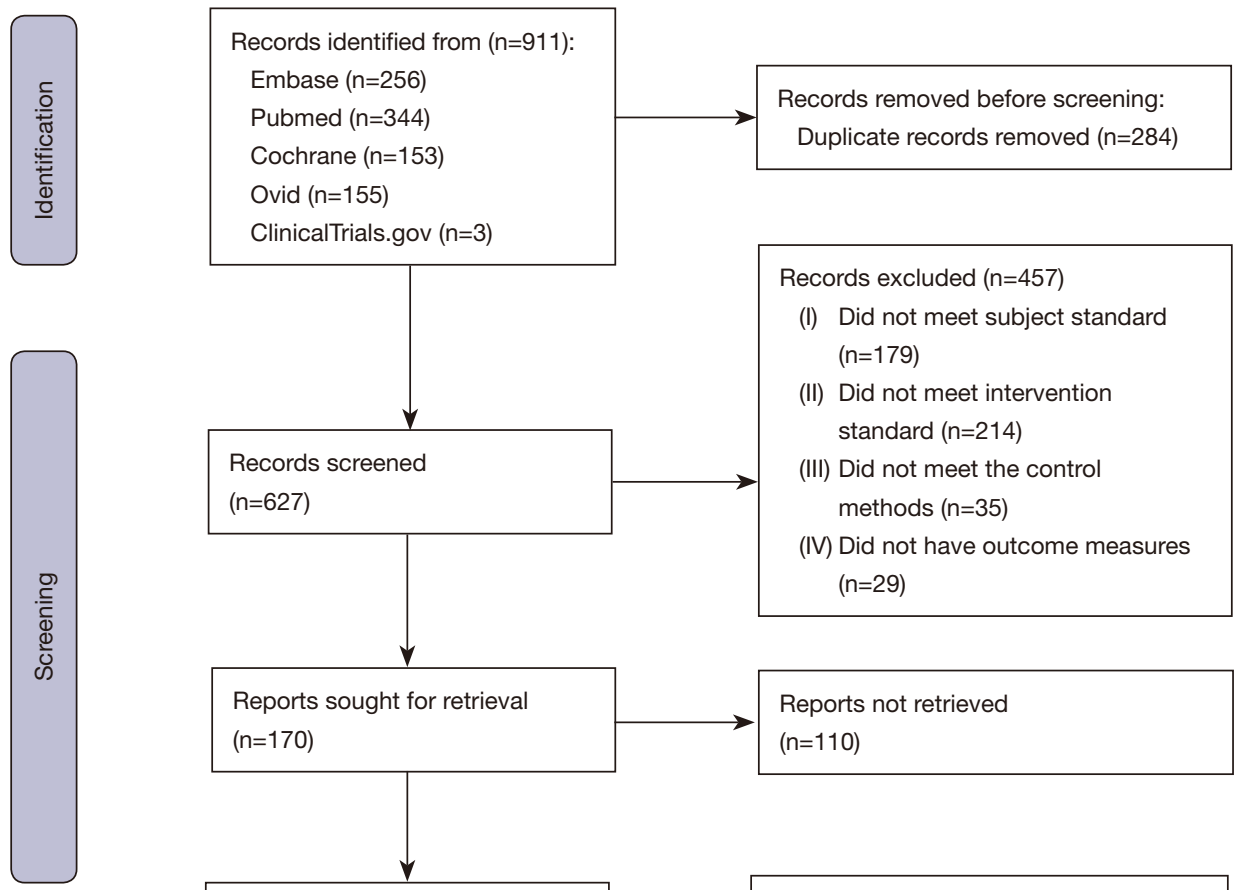

Ovid $(n=155)$

ClinicalTrials.gov $(n=3)$
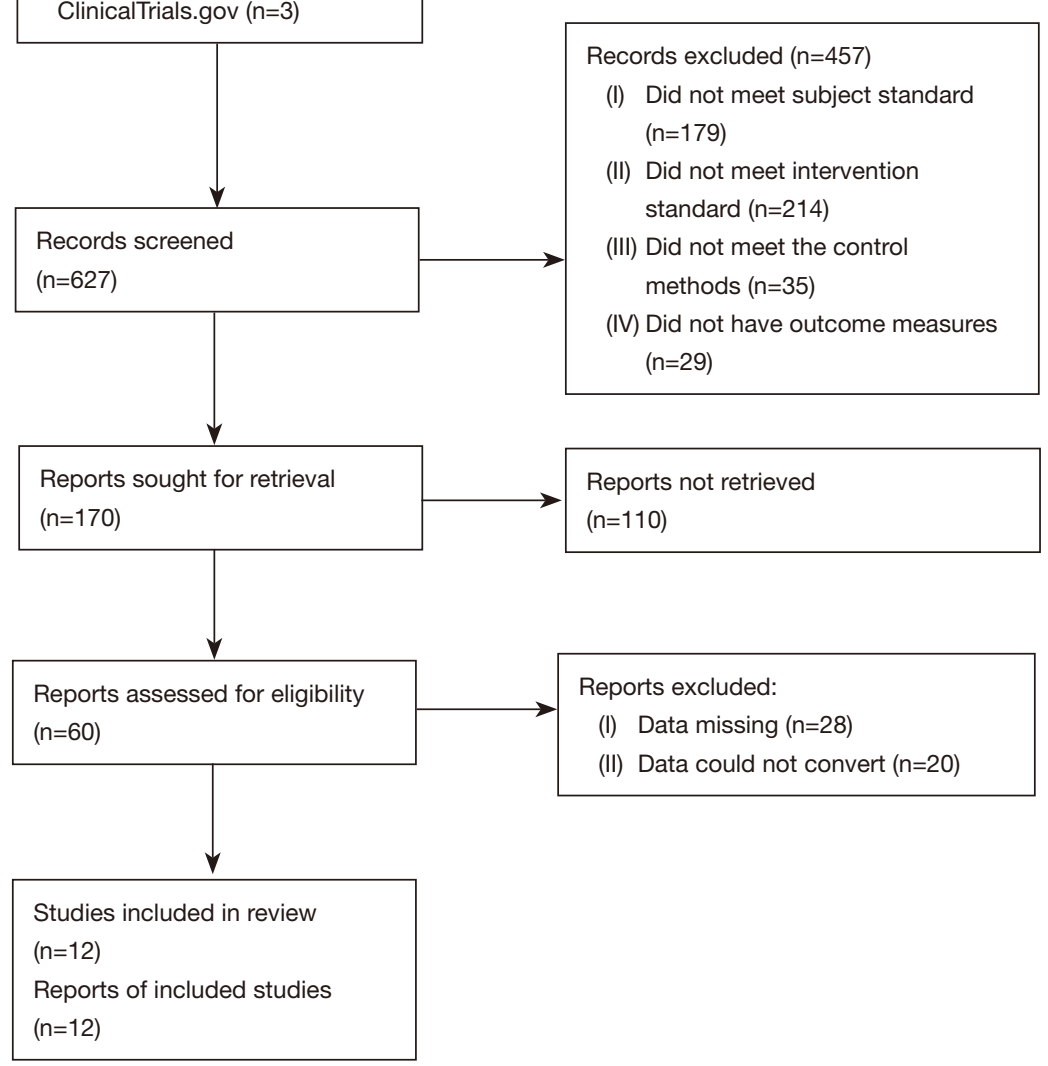

Reports excluded:

(I) Data missing $(\mathrm{n}=28)$

(II) Data could not convert $(n=20)$

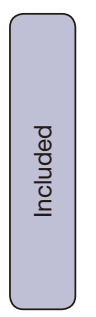

Figure 1 Flowchart of the selection process.

Table 1 Basic characteristics, intervention measures, and rehabilitation indicators of the included literature

\begin{tabular}{|c|c|c|c|c|c|c|c|}
\hline Author & Groups & Sample & $\begin{array}{c}\text { Sex } \\
\text { (male:female) }\end{array}$ & Age (years) & Intervention & Frequency & Outcomes \\
\hline \multirow[t]{2}{*}{$\begin{array}{l}\text { McKay } \\
\text { et al. (7), } 2012\end{array}$} & $E$ & 10 & $5: 5$ & $63.51 \pm 4.93$ & $\begin{array}{l}10 \text { minutes warm-up, } 2 \text { groups } \\
\text { of lower limb exercises, } 8 \text { in each } \\
\text { group (standing leg lifting, sitting leg } \\
\text { pressing, leg curling, knee extension) }\end{array}$ & $\begin{array}{l}3 \text { times a week } \\
\text { for } 6 \text { weeks }\end{array}$ & (I), (II), (III), (IV) \\
\hline & C & 12 & $4: 8$ & $60.58 \pm 8.05$ & Routine nursing & & \\
\hline $\begin{array}{l}\text { Tungtrongjit } \\
\text { et al. (8), } 2012\end{array}$ & C & 30 & $6: 24$ & $65.90 \pm 7.20$ & Routine nursing & - & \\
\hline
\end{tabular}

Table 1 (continued) 
Table 1 (continued)

\begin{tabular}{|c|c|c|c|c|c|c|c|}
\hline Author & Groups & Sample & $\begin{array}{c}\text { Sex } \\
\text { (male:female) }\end{array}$ & Age (years) & Intervention & Frequency & Outcomes \\
\hline \multirow[t]{2}{*}{$\begin{array}{l}\text { Calatayud } \\
\text { et al. (9), } 2017\end{array}$} & $E$ & 22 & - & $66.80 \pm 4.80$ & $\begin{array}{l}15 \text { minutes warm-up exercise and } \\
\text { joint activity, } 2 \text { groups of self-weight } \\
\text { training, each group repeated } 20 \text { times }\end{array}$ & $\begin{array}{l}3 \text { days per week } \\
\text { for } 8 \text { weeks }\end{array}$ & $\begin{array}{l}\text { (II), (III), (IV), (V), } \\
\text { (VII), (VIII) }\end{array}$ \\
\hline & $\mathrm{C}$ & 22 & - & $66.70 \pm 3.10$ & Routine nursing & - & \\
\hline $\begin{array}{l}\text { Matassi et al. } \\
(10), 2014\end{array}$ & $\mathrm{C}$ & 61 & $35: 26$ & $67.00 \pm 7.70$ & Routine nursing & - & \\
\hline \multirow[t]{2}{*}{$\begin{array}{l}\text { Kim et al. (11), } \\
2021\end{array}$} & $E$ & 20 & $10: 10$ & $67.4 \pm 6.0$ & $\begin{array}{l}\text { Water sports therapists guide muscle } \\
\text { stretching and resistance exercises in } \\
\text { warm water }\end{array}$ & $\begin{array}{l}\text { three times a } \\
\text { week, and for } \\
60 \text { min each } \\
\text { time for } \\
4-8 \text { weeks }\end{array}$ & (II) \\
\hline & $\mathrm{C}$ & 23 & $14: 9$ & $66.9 \pm 6.3$ & Routine nursing & - & \\
\hline \multirow[t]{2}{*}{$\begin{array}{l}\text { An et al. (12), } \\
2021\end{array}$} & $E$ & 18 & - & $71.1 \pm 3.30$ & $\begin{array}{l}\text { Remote rehabilitation instruction: } \\
\text { including warm-up, mobility, flexibility, } \\
\text { strength and balance training }\end{array}$ & $\begin{array}{l}2 \text { times/day, } \\
5 \text { days/week for } \\
3 \text { weeks }\end{array}$ & (II), (V), (VIII) \\
\hline & $\mathrm{C}$ & 18 & - & $70.38 \pm 2.59$ & Routine nursing & - & \\
\hline \multirow[t]{2}{*}{$\begin{array}{l}\text { Beaupre et al. } \\
(13), 2004\end{array}$} & $E$ & 65 & $26: 39$ & $67.00 \pm 7.00$ & $\begin{array}{l}\text { Resistance training and endurance } \\
\text { training }\end{array}$ & $\begin{array}{l}\text { three times a } \\
\text { week for } \\
4 \text { weeks }\end{array}$ & (II), (III), (V), (VI) \\
\hline & $\mathrm{C}$ & 66 & $33: 33$ & $67.00 \pm 6.00$ & Routine nursing & - & \\
\hline $\begin{array}{l}\text { Blasco et al. } \\
(15), 2020\end{array}$ & $\mathrm{C}$ & 26 & $11: 15$ & $70.90 \pm 9.50$ & Live as usual & - & \\
\hline \multirow[t]{2}{*}{$\begin{array}{l}\text { Domínguez- } \\
\text { Navarro et al. } \\
(16), 2021\end{array}$} & $E$ & 20 & $7: 13$ & $70.40 \pm 6.40$ & Balance and proprioception training & $\begin{array}{l}12 \text { training } \\
\text { sessions for } \\
4 \text { weeks }\end{array}$ & $\begin{array}{l}(\mathrm{V}),(\mathrm{VI}),(\mathrm{VIII}), \\
(\mathrm{IX})\end{array}$ \\
\hline & $\mathrm{C}$ & 21 & $7: 14$ & $70.20 \pm 5.60$ & Live as usual & - & \\
\hline \multirow[t]{2}{*}{$\begin{array}{l}\text { Villadsen et al. } \\
\text { (17), } 2014\end{array}$} & $\mathrm{E}$ & 84 & $37: 47$ & $67.9 \pm 8.6$ & $\begin{array}{l}\text { Chair stands, knee bends, muscle } \\
\text { extention }\end{array}$ & 8 weeks training & (III), (IV) \\
\hline & $\mathrm{C}$ & 81 & $36: 45$ & $66.9 \pm 8.3$ & Routine nursing & & \\
\hline \multirow{2}{*}{$\begin{array}{l}\text { Mitchell et al. } \\
(18), 2005\end{array}$} & $\mathrm{E}$ & 57 & $27: 30$ & $70.6 \pm 8.2$ & Knee flexion and extension & 8 weeks training & (II), (III) \\
\hline & $\mathrm{C}$ & 57 & $21: 36$ & $70.0 \pm 7.2$ & Routine nursing & & \\
\hline
\end{tabular}

Rehabilitation index: (I) Flat Surface Walking Test; (II) The Western Ontario and McMaster Universities Osteoarthritis Index (WOMAC); (III) The Short Form 36 (SF-36); (IV) Visual analog scale; (V) knee range of motion (ROM); (VI) quadriceps strength; (VII) Stair-climbing test; (VIII) Timed Up and Go; (IX) The Knee Injury and Osteoarthritis Outcome Score. E, experimental group; C, control group. 
Table 2 Risk of bias assessment based on the Cochrane Collaboration criteria

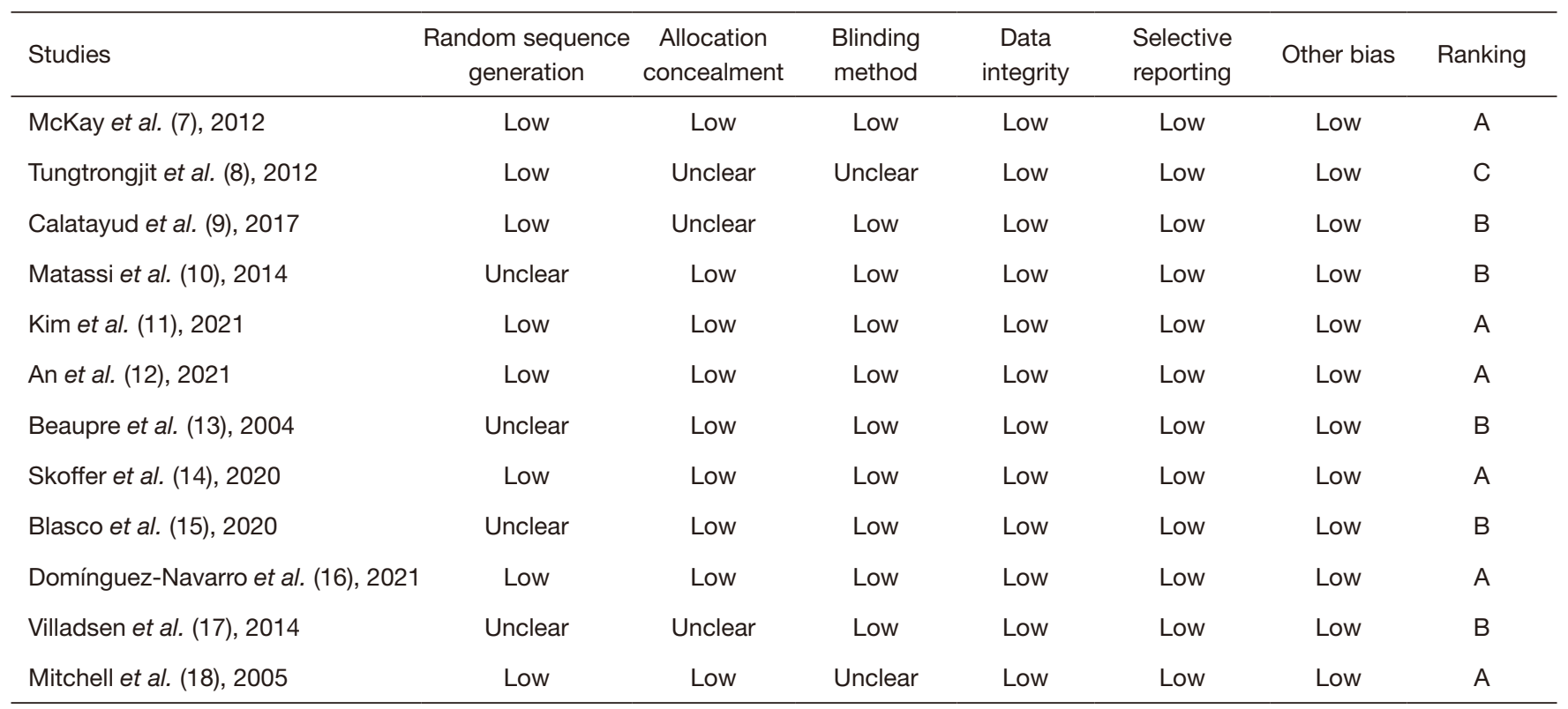

A, level A; B, level B; C, level C.

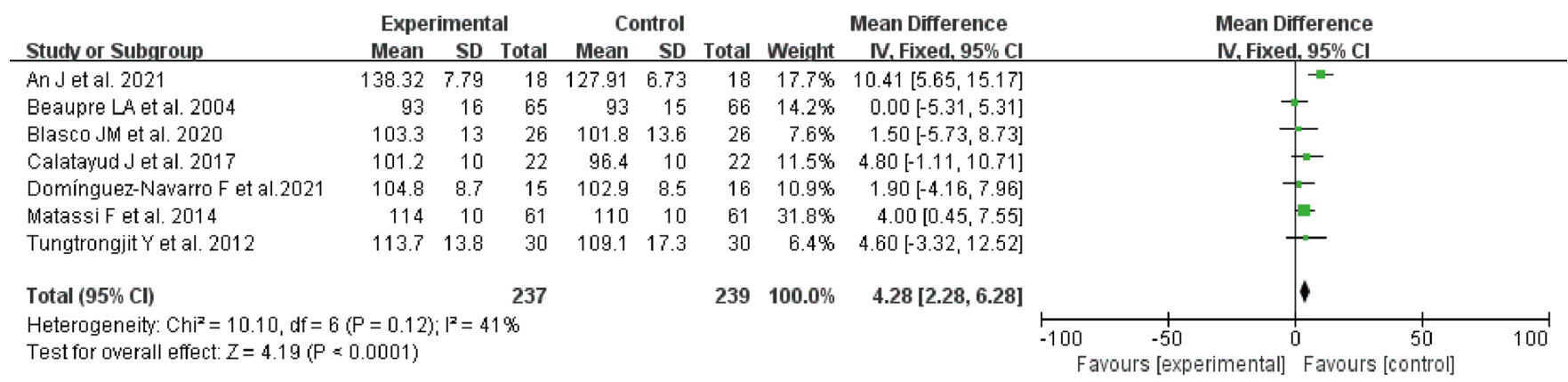

Figure 2 Forest plot of the effect of preoperative exercise intervention on postoperative ROM. ROM, range of motion.

12 weeks. The number of patients dropped that out at each observation point was statistically analyzed. The data of 10 articles remained complete. There were 4 articles $(10,13,15,17)$ in which the randomization method was specified but in which the grouping method was not clear, and 3 articles $(8,9,18)$ in which the intervention blind method or data collection blind method was not specified. Selective reporting bias and other biases were not observed. The detailed risk of bias and literature quality level are summarized in Table 2.

\section{Meta-analysis result}

Effect of preoperative exercise intervention on postoperative knee ROM

A total of 7 articles $(8-10,12,13,15,16)$ reported the postoperative knee ROM indicators, and there was no statistical between them $\left(\mathrm{I}^{2}=41 \% ; \mathrm{P}=0.12\right)$. The fixed effects model was used. Meta-analysis showed that there was significant difference in ROM flexion between the two groups $(\mathrm{MD}=4.28,95 \% \mathrm{CI}: 2.28$ to $6.28 ; Z=4.19$; $\mathrm{P}<0.0001)$ as shown in Figure 2. 


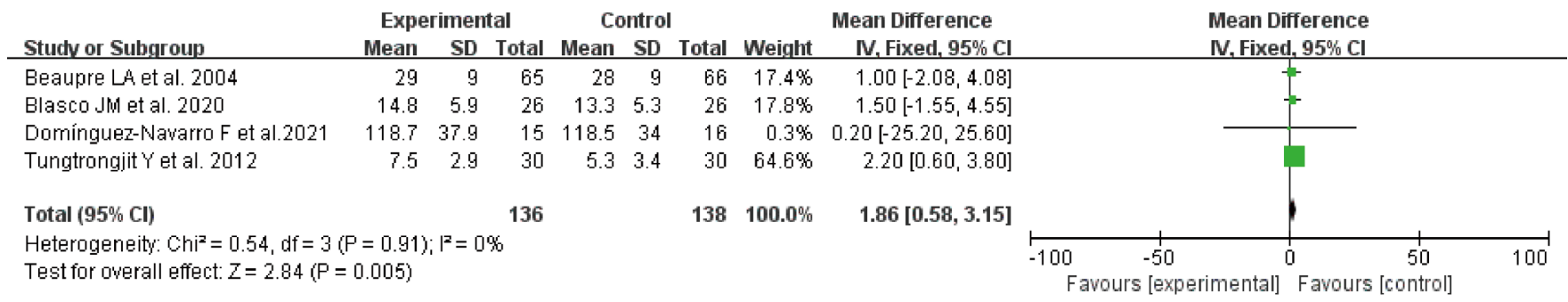

Figure 3 Forest plot of the effect of preoperative exercise intervention on quadriceps strength after surgery.

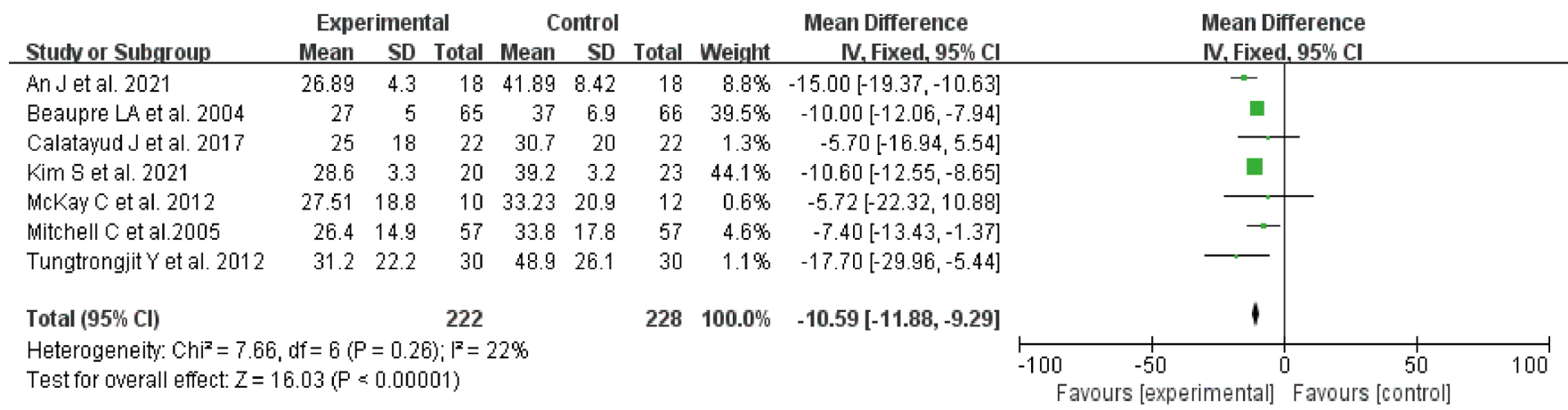

Figure 4 Forest plot of the effect of preoperative exercise intervention on postoperative WOMAC score. WOMAC, The Western Ontario and McMaster Universities Osteoarthritis Index.

\section{Effect of preoperative exercise intervention on quadriceps strength after surgery}

A total of 4 articles $(8,13,15,16)$ reported postoperative quadriceps strength indicators and showed statistical heterogeneity $\left(\mathrm{I}^{2}=0 \% ; \mathrm{P}=0.91\right)$. The fixed effects model was thus used. Meta-analysis showed that there was significant difference in quadriceps strength values between the two groups ( $M D=1.86 ; 95 \%$ CI: $0.58-3.15 ; \mathrm{Z}=2.84 ; \mathrm{P}=0.005)$ as shown in Figure 3.

\section{Effect of preoperative exercise intervention on postoperative arthritis index score (WOMAC)}

This indicator was reported in 7 articles $(7-9,11-13,17)$. The articles showed statistical homogeneity $\left(\mathrm{I}^{2}=22 \%, \mathrm{P}=0.26\right)$, and the fixed effects model was used. Meta-analysis showed that there was significant difference in WOMAC score between the two groups ( $M D=-10.59 ; 95 \% \mathrm{CI}:-11.88$ to -9.29; $\mathrm{Z}=16.03 ; \mathrm{P}<0.00001)$ as shown in Figure 4.
Effect of preoperative exercise intervention on postoperative standing and walking test (TUG) score This statistic was reported in 5 articles $(9,12,14-16)$. The articles showed statistical homogeneity $\left(\mathrm{I}^{2}=20 \% ; \mathrm{P}=0.28\right)$, and the fixed effects model was used. Meta-analysis showed that there was significant difference in TUG score between the two groups $(\mathrm{MD}=-1.29 ; 95 \% \mathrm{CI}:-1.90$ to -0.67 ; $\mathrm{Z}=4.08 ; \mathrm{P}<0.0001)$ as shown in Figure 5 .

\section{Effect of preoperative exercise intervention on postoperative SF-36 score}

SF-36 score was reported in 5 articles $(7,9,13,17,18)$, which showed statistical homogeneity $\left(\mathrm{I}^{2}=0 \% ; \mathrm{P}=0.42\right)$, and a fixed effects model was used. There was a significant difference in the quality of life score values between the two groups ( $M D=1.66$; 95\% CI: 1.13-2.20; Z=6.08; $\mathrm{P}<0.00001$ ) as shown in Figure 6.

\section{Sensitivity analysis and publication bias analysis}

As there was no heterogeneity among the articles in the 


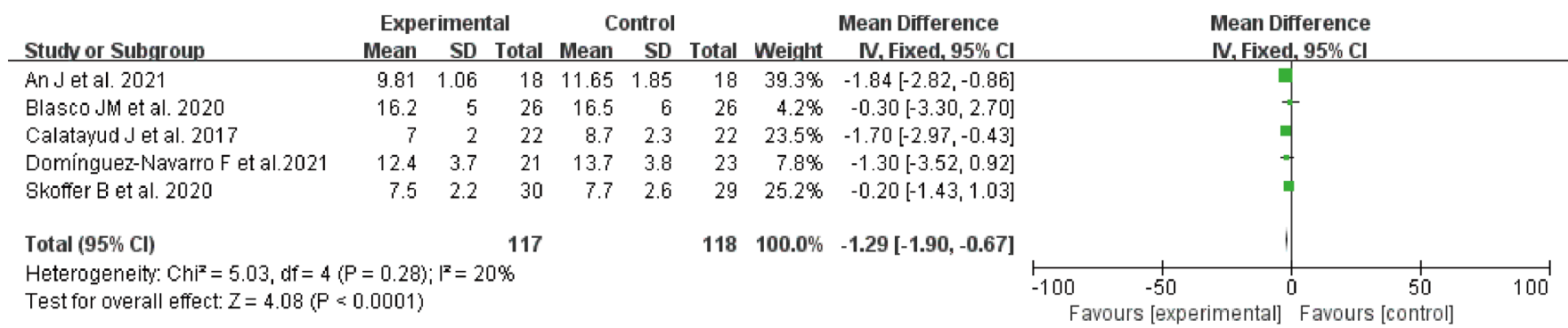

Figure 5 Forest plot of the effect of preoperative exercise intervention on postoperative TUG score. TUG, Timed Up and Go.

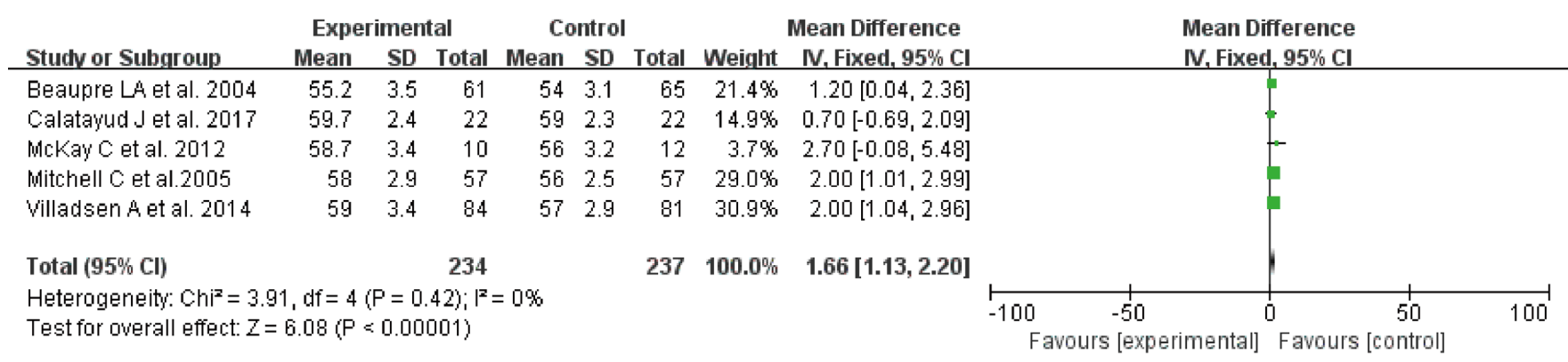

Figure 6 Forest plot of the effect of preoperative exercise intervention on the postoperative SF-36 score. SF-36, The Short Form 36 of Quality of Life.

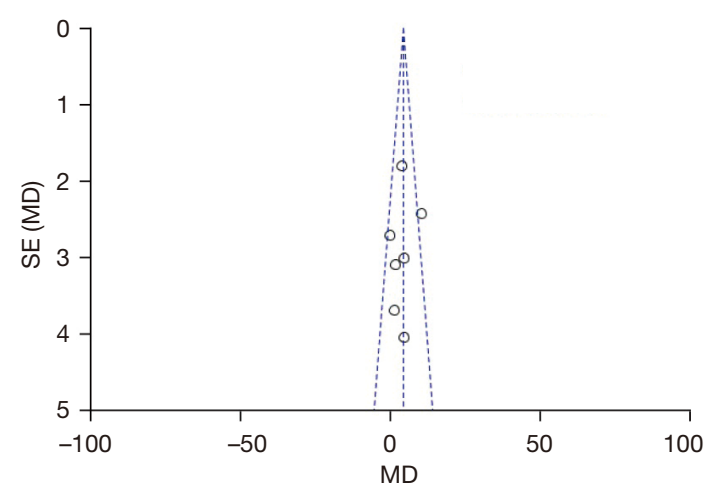

Figure 7 Funnel plot of the ROM index. MD, mean difference; SE, standard error; ROM, range of motion.

meta-analysis of the above 5 indicators, no sensitivity analysis was performed. The funnel plot of the ROM index with the highest number of included articles showed that the two groups of funnels were unevenly distributed on both sides, suggesting a possible publication bias, as shown in Figure 7.

\section{Discussion}

TKA is a surgery that entails considerable trauma, bleeding, severe stress, and postoperative complications. Perioperative rehabilitation training directly determines whether the surgery can be successful (19). In addition to age, fracture severity, preoperative sedation and postoperative nursing, preoperative rehabilitation exercise is another intervention method that can affect the postoperative rehabilitation effect of TKA (20). Researchers have long focused on postsurgery motor rehabilitation, but related studies $(7,8)$ have shown that pre-operative functional exercise is of great significance for the early rehabilitation after surgery. Thus far, many such studies have been published. The study by Liu et al. (21) involved a literature review and meta-analysis, the results of which showed that patients who received preoperative exercise intervention had less postoperative 6WMT score, less pain, and fewer adverse reactions. In our study, more RCTs were included (a total number of 10), and the reported outcome indicators were different 
from the previous meta-analysis mentioned. Our results showed that for the patients who received preoperative exercise intervention, the knee flexion at 6-12 weeks after operation was wider ( $M D=4.60 ; \mathrm{P}<0.0001)$, the quadriceps strength value was stronger $(\mathrm{MD}=1.86 ; \mathrm{P}=0.005)$, the arthritis index score (WOMAC) was less $(\mathrm{MD}=-10.74$; $\mathrm{P}<0.0001)$, the time taken for standing up and walking test was less ( $M D=-1.29 ; \mathrm{P}<0.001)$, but the early quality of life score was higher $(\mathrm{MD}=1.15, \mathrm{P}=0.008)$ than the corresponding measures in the control group, suggesting that preoperative exercise intervention can improve the early rehabilitation effect after surgery. The preoperative exercise intervention for patients undergoing TKA surgery can help patients exercise the lower limb muscles, including the muscles around the knee, which enhances the muscle strength of the flexor and extensor muscles around the knee, improves the stability of the knee joint, and helps reduce the occurrence of postoperative complications (such as lower extremity deep venous thrombosis, prosthesis instability or dislocation, and infectious events) (22). In addition, preoperative exercise intervention can improve patients' negative emotions, reduce stress reactions during surgery, and promote wound healing (23). A few studies (24) compared the effect of preoperative exercise between TKA surgery and total hip arthroplasty (THA) surgery, and found that preoperative exercise was equally effective for both surgeries. The active and passive movement of the knee joint before operation also can improve the lower limb or local blood circulation, effectively prevent joint adhesion or mechanization, and reduce some early postoperative complications, such as embolic events (lower limb venous thrombosis, pulmonary embolism), prosthesis related events (dislocation, prosthesis instability, device abnormality, etc.) and infectious events (superficial infection and deep infection) (25).

Although preoperative exercise intervention is effective, there is no uniform guideline for the intervention time, frequency, or the measures of the exercise. McDonald et al. (26) pointed out that the limb function exercise guided by professional rehabilitation training nurses 3-8 weeks before operation could enable patients to fully understand the essentials and functions of movement in the long-term exercise process, improve the muscle strength and the flexibility of joint capsule before operation, and significantly reduce the discomfort of postoperative exercise, also improve the patient's compliance and achieve satisfactory results. In the 10 included articles of this study, the intervention time was 4-8 weeks before surgery, and the forms of exercise were also different. The intervention measures mostly started with a warm-up exercise, followed by a certain amount of mobility, flexibility, strength, and balance training exercise, and finally concluded with a relaxation exercise, with an intervention frequency of 2-5 times/week. One article (11) reported a method of aquatic exercise, involving completing muscle stretching and resistance exercise in warm water, which achieved satisfactory results; another study (12) reported a method of telerehabilitation guidance, involving completing exercise intervention under the remote guidance of experts, which is suitable for patients exercising at home. Despite measures varied, all of these studies suggested that, care should be taken due to the vulnerability of the patients to avoid unnecessary injury.

The meta-analysis in this study only collected the data in the early postoperative period (6-12 weeks) in the literature, and did not investigate the long-term effects of preoperative exercise. One study reported (10) that at 6-month and 1-year postoperative follow-up, the ROM of knee flexion of the two groups of patients would getting close, indicating that the effect of preoperative exercise intervention is effective in the early postoperative period, but its long-term effect remains unclear.

In this study, sensitivity analysis was not performed because statistical heterogeneity was not found between the articles. However, the funnel plot showed that both sides were asymmetric, which may be related to the small number of included studies. Therefore, more RCTs with good quality and more number of samples should be included for the further study of this topic.

\section{Conclusions}

This meta-analysis included 10 articles with a total of 610 patients. The results showed that preoperative exercise intervention before TKA could improve knee flexion and flexibility, reduce inflammatory pain and stiffness, and improve muscle strength and joint function, thereby improving the quality of life of patients. Due to the small 
number of articles included in this study, the subject remains to be further explored in a randomized controlled study with a larger sample size.

\section{Acknowledgments}

Funding: Funded by Chengdu Science and Technology Bureau project, project number: 2019-YF05-00467$\mathrm{SN}$, project name: research and development of a digital platform for accurate functional assessment of osteoarthritis and exercise guidance.

\section{Footnote}

Reporting Checklist: The authors have completed the PRISMA reporting checklist. Available at https://dx.doi. org/10.21037/apm-21-2670

Conflicts of Interest: All authors have completed the ICMJE uniform disclosure form (available at https://dx.doi. org/10.21037/apm-21-2670). The authors have no conflicts of interest to declare.

Ethical Statement: The authors are accountable for all aspects of the work in ensuring that questions related to the accuracy or integrity of any part of the work are appropriately investigated and resolved.

Open Access Statement: This is an Open Access article distributed in accordance with the Creative Commons Attribution-NonCommercial-NoDerivs 4.0 International License (CC BY-NC-ND 4.0), which permits the noncommercial replication and distribution of the article with the strict proviso that no changes or edits are made and the original work is properly cited (including links to both the formal publication through the relevant DOI and the license). See: https://creativecommons.org/licenses/by-nc-nd/4.0/.

\section{References}

1. Gränicher P, Stöggl T, Fucentese SF, et al. Preoperative exercise in patients undergoing total knee arthroplasty: a pilot randomized controlled trial. Arch Physiother 2020;10:13.

2. Wirries N, Ezechieli M, Stimpel K, et al. Impact of continuous passive motion on rehabilitation following total knee arthroplasty. Physiother Res Int 2020;25:e1869.

3. Franz A, Queitsch FP, Behringer M, et al. Blood flow restriction training as a prehabilitation concept in total knee arthroplasty: A narrative review about current preoperative interventions and the potential impact of BFR. Med Hypotheses 2018;110:53-9.

4. Liao CD, Tsauo JY, Huang SW, et al. Preoperative range of motion and applications of continuous passive motion predict outcomes after knee arthroplasty in patients with arthritis. Knee Surg Sports Traumatol Arthrosc 2019;27:1259-69.

5. Chen H, Li S, Ruan T, et al. Is it necessary to perform prehabilitation exercise for patients undergoing total knee arthroplasty: meta-analysis of randomized controlled trials. Phys Sportsmed 2018;46:36-43. Erratum in: Phys Sportsmed 2018;46:399-403. .

6. Walker LC, Clement ND, Deehan DJ. Predicting the Outcome of Total Knee Arthroplasty Using the WOMAC Score: A Review of the Literature. J Knee Surg 2019;32:736-41.

7. McKay C, Prapavessis H, Doherty T. The effect of a prehabilitation exercise program on quadriceps strength for patients undergoing total knee arthroplasty: a randomized controlled pilot study. PM R 2012;4:647-56.

8. Tungtrongjit $\mathrm{Y}$, Weingkum P, Saunkool P. The effect of preoperative quadriceps exercise on functional outcome after total knee arthroplasty. J Med Assoc Thai 2012;95 Suppl 10:S58-66.

9. Calatayud J, Casaña J, Ezzatvar Y, et al. High-intensity preoperative training improves physical and functional recovery in the early post-operative periods after total knee arthroplasty: a randomized controlled trial. Knee Surg Sports Traumatol Arthrosc 2017;25:2864-72.

10. Matassi F, Duerinckx J, Vandenneucker H, et al. Range of motion after total knee arthroplasty: the effect of a preoperative home exercise program. Knee Surg Sports Traumatol Arthrosc 2014;22:703-9.

11. Kim S, Hsu FC, Groban L, et al. A pilot study of aquatic prehabilitation in adults with knee osteoarthritis undergoing total knee arthroplasty - short term outcome. BMC Musculoskelet Disord 2021;22:388.

12. An J, Ryu HK, Lyu SJ, et al. Effects of Preoperative Telerehabilitation on Muscle Strength, Range of Motion, and Functional Outcomes in Candidates for Total Knee Arthroplasty: A Single-Blind Randomized Controlled Trial. Int J Environ Res Public Health 2021;18:6071. 13. Beaupre LA, Lier D, Davies DM, et al. The effect of a 
preoperative exercise and education program on functional recovery, health related quality of life, and health service utilization following primary total knee arthroplasty. J Rheumatol 2004;31:1166-73.

14. Skoffer B, Maribo T, Mechlenburg I, et al. Efficacy of preoperative progressive resistance training in patients undergoing total knee arthroplasty: 12-month followup data from a randomized controlled trial. Clin Rehabil 2020;34:82-90.

15. Blasco JM, Acosta-Ballester Y, Martínez-Garrido I, et al. The effects of preoperative balance training on balance and functional outcome after total knee replacement: a randomized controlled trial. Clin Rehabil 2020;34:182-93.

16. Domínguez-Navarro F, Silvestre-Muñoz A, IgualCamacho C, et al. A randomized controlled trial assessing the effects of preoperative strengthening plus balance training on balance and functional outcome up to 1 year following total knee replacement. Knee Surg Sports Traumatol Arthrosc 2021;29:838-48.

17. Villadsen A, Overgaard S, Holsgaard-Larsen A, et al. Postoperative effects of neuromuscular exercise prior to hip or knee arthroplasty: a randomised controlled trial. Ann Rheum Dis 2014;73:1130-7.

18. Mitchell C, Walker J, Walters S, et al. Costs and effectiveness of pre- and post-operative home physiotherapy for total knee replacement: randomized controlled trial. J Eval Clin Pract 2005;11:283-92.

19. Soeters R, White PB, Murray-Weir M, et al. Preoperative Physical Therapy Education Reduces Time to Meet Functional Milestones After Total Joint Arthroplasty. Clin Orthop Relat Res 2018;476:40-8.

20. Roger C, Debuyzer E, Dehl M, et al. Factors associated

Cite this article as: Wang D, Wu T, Li Y, Jia L, Ren J, Yang L. A systematic review and meta-analysis of the effect of preoperative exercise intervention on rehabilitation after total knee arthroplasty. Ann Palliat Med 2021;10(10):10986-10996. doi: 10.21037/apm-21-2670 with hospital stay length, discharge destination, and 30-day readmission rate after primary hip or knee arthroplasty: Retrospective Cohort Study. Orthop Traumatol Surg Res 2019;105:949-55.

21. Liu H, Cong H, Chen L, et al. Efficacy and Safety of Lower Limb Progressive Resistance Exercise for Patients With Total Knee Arthroplasty: A Meta-analysis of Randomized Controlled Trials. Arch Phys Med Rehabil 2021;102:488-501.

22. Bade MJ, Kittelson JM, Kohrt WM, et al. Predicting functional performance and range of motion outcomes after total knee arthroplasty. Am J Phys Med Rehabil 2014;93:579-85.

23. Moyer R, Ikert K, Long K, et al. The Value of Preoperative Exercise and Education for Patients Undergoing Total Hip and Knee Arthroplasty: A Systematic Review and MetaAnalysis. JBJS Rev 2017;5:e2.

24. Rooks DS, Huang J, Bierbaum BE, et al. Effect of preoperative exercise on measures of functional status in men and women undergoing total hip and knee arthroplasty. Arthritis Rheum 2006;55:700-8.

25. Wallis JA, Taylor NF. Pre-operative interventions (nonsurgical and non-pharmacological) for patients with hip or knee osteoarthritis awaiting joint replacement surgery-a systematic review and meta-analysis. Osteoarthritis Cartilage 2011;19:1381-95.

26. McDonald S, Page MJ, Beringer K, et al. Preoperative education for hip or knee replacement. Cochrane Database Syst Rev 2014;2014:CD003526.

(English Language Editor: J. Gray) 